\title{
Tailoring the electrode-electrolyte interface of Solid Oxide Fuel Cells (SOFC) by laser micro-patterning to improve their electrochemical performance
}

\author{
J. A. Cebollero, R. Lahoz, M. A. Laguna-Bercero and A. Larrea* \\ Instituto de Ciencia de Materiales de Aragón, U. Zaragoza-CSIC, C/ María de Luna 3, E- \\ 50.018 Zaragoza, Spain.
}

\section{A B S T R A C T}

Cathode activation polarisation is one of the main contributions to the losses of a Solid Oxide Fuel Cell. To reduce this loss we use a pulsed laser to modify the surface of yttria stabilized zirconia (YSZ) electrolytes to make a corrugated micro-patterning in the mesoscale. The beam of the laser source, $5 \mathrm{~ns}$ pulse width and emitting at $\lambda=532 \mathrm{~nm}$ (green region), is computer-controlled to engrave the selected micro-pattern on the electrolyte surface. Several laser scanning procedures and geometries have been tested. Finally, we engrave a square array with $28 \mu \mathrm{m}$ of lattice parameter and $7 \mu \mathrm{m}$ in depth on YSZ plates. With these plates we prepare LSM-YSZ/YSZ/LSM-YSZ symmetrical cells (LSM: $\mathrm{La}_{1-\mathrm{x}} \mathrm{Sr}_{\mathrm{x}} \mathrm{MnO}_{3}$ ) and determine their activation polarisation by Electrochemical Impedance Spectroscopy (EIS). To get good electrode-electrolyte contact after sintering it is necessary to use pressure-assisted sintering with low loads (about $5 \mathrm{kPa}$ ), which do not modify the electrode microstructure. The decrease in polarisation with respect to an unprocessed cell is about $30 \%$. EIS analysis confirms that the reason for this decrease is an improvement in the activation processes at the electrodeelectrolyte interface.

Keywords: SOFC; Laser machining; Corrugated surface; Electrode polarisation; Cathode activation; Electrode/electrolyte interface

* Corresponding author.

E-mail address: alarrea@unizar.es (A. Larrea).

Tel: +34876555125

Fax: +34 976761957 


\section{Introduction}

Solid Oxide Fuel Cells (SOFC) are electrochemical devices that directly transform the chemical energy stored in a fuel into electricity with high efficiency and zero, or very low, emission of pollutants. The core of the cell is the electrolyte, a solid oxide that is able to transport ions at high temperature, usually $600-900{ }^{\circ} \mathrm{C}$. Among all the different types of fuel cells, the high temperature operation of SOFCs offers special characteristics that make them very attractive in the desired evolution from the present fossil fuel-based economy to a greener economy based on renewable sources of energy. For instance, SOFCs don't need expensive catalysers as noble metals because the Ni content in the anode and various types of solid oxides in the cathode are able to catalyse the reactions at high temperature. Furthermore, they can be fuelled with hydrocarbons, in addition to hydrogen, because the waste heat produced by the electrochemical reactions can be used for external or internal fuel reforming. It should finally be noted that SOFCs also provide hot water as a secondary product, which can be harnessed for, among other things, home heating [1].

The most determinant parameters for the cell performance are the activation energy and thickness of the electrolyte, usually comprised of yttria stabilised zirconia (YSZ) the most used material [2],[3]. In this way, low intermediate temperature applications need thin film electrolytes supported by one of the electrodes, usually the anode [4]. Conversely, electrolytesupported cells require high temperature operation to reduce the ohmic impedance of the cell [5]. Once the value of the electrolytic ohmic impedance has been reduced to fit the cell requirements, the main factor in determining the cell losses is the activation polarisation of the cathode, because anode kinetics for $\mathrm{H}_{2}$ oxidation is significantly faster than cathode kinetics for oxygen reduction [6]. Cathodic polarisation depends on the ability of the cell to carry out the oxygen reduction reactions (ORR) at the electrolyte-cathode interface followed by the oxide ion incorporation into the electrolyte [5],[7]. Apart from an appropriate chemical compound selection, the most obvious way to promote charge transfer is to increase the triplephase boundary (TPB) region, where the electrochemical reactions take place. There, the oxygen molecules have simultaneous access to the electronic and ionic conductive phases. For composite cathode materials formed with an electronic conducting oxide, such as LSM (LSM: lanthanum strontium manganite), and an ionic conductor, the TPB region is a line (1D). In fact it has been shown in porous $\mathrm{La}_{0.6} \mathrm{Ca}_{0.4} \mathrm{MnO}_{3}-\mathrm{YSZ}$ composite cathodes that the reaction rate was essentially proportional to the TPB length [8]. However, in the case of mixed ionic 
electronic conductors (MIEC), such as LSCF, the reaction sites are distributed in a two-phase (gas-electrode) 2D surface [9].

Although the possible ORR sites are distributed throughout the electrode, whether the cathode is two-phase or single phase, they are not equally active because the electrochemical reactions take place preferentially at the vicinity of the cathode/electrolyte interface, typically within about $10 \mu \mathrm{m}[10],[11]$. The relationship between the current density, $j$, and the cathodic activation loss, $\eta_{a c}^{c}$, is established by the phenomenological non-linear ButlerVolmer equation [12]:

$j=j_{0}\left\{\exp \left[\frac{\beta z F \eta_{a c}^{c}}{R T}\right]-\exp \left[\frac{(1-\beta) z F \eta_{a c}^{c}}{R T}\right]\right\}$

where $\mathrm{T}$ is the absolute temperature, $\mathrm{R}$ and $\mathrm{F}$ the gas and Faraday constants respectively, $z$ the number of electrons participating in the reaction, $\beta$ the charge transfer coefficient and $j_{0}$ is known as the exchange current density. The exchange current density depends upon the size and number of electrocatalyst particles at the electrolyte surface. Thus, if the electrolytecathode surface is corrugated, $j_{0}$ can be, in turn, approximated by the product of the intrinsic exchange current density on a perfectly smooth surface, $j_{0}{ }^{\prime}$, by an area enlargement factor defined as the ratio between the actual (corrugated) surface, $A$, and the projected area, $A^{\prime}[13]$ : $j_{0}=j_{0}{ }^{\prime}\left(A / A^{\prime}\right)$

One option to increase the number of reaction sites at the cathode is to impregnate it with nanoparticles at the area near the interface, which will directly increase the $j_{0}$ ' factor [14],[15], although this approach usually presents durability concerns [16]. A different strategy is to increase the macroscopic electrolyte-cathode contact area, acting on the $A / A$ ' ratio. In the micro-SOFC scale application, which usually involves devices in the $\mathrm{mW}$ power range fabricated using Si-based semiconductor MEMS (Micro-Electro-Mechanical Systems) technology, several types of templates at the nanoscale have been used to develop membraneelectrode assemblies (MEA) with significant area enlargement factors. For instance Chao et al. fabricated corrugated MEA by coating a template fabricated by nanosphere lithography with a $80 \mathrm{~nm}$ thick YSZ film, obtaining a 30\% decrease in the activation polarisation [17]. Moreover, Motoyama et al. fabricated Ni-YSZ-Pt nanotubular arrays ( $\sim 5 \mathrm{~m}$ in length, $0.5 \mu \mathrm{m}$ outside diameter, $50 \mathrm{~nm}$ in thickness) with an area enlargement factor of 20 [18]. However, in addition to low OCV and low power values in the latter case, these ultrathin devices usually present long-term stability issues due to degradation of the electrodes [19]. On the other hand, 
for the large-scale applications, different methods based on ceramic technology have been explored. For instance, Herbstritt et al. reported a decrease in the cathode resistance of LSM/YSZ/LSM symmetrical cathode cells where $\sim 10 \mu \mathrm{m}$ YSZ particles were screen-printed on the YSZ electrolytic substrate to enlarge the active surface [20]. Then, Gao et al. also reduced the cathode polarisation of LSM-YSZ cells by increasing the surface roughness of the YSZ electrolyte using atmospheric plasma spraying [21],[22],[23]. Xu et al. developed imprinted micro-patterns on the electrolyte to improve the SOFC performance [24],[25],[26]. Recently, Dai et al. published a different technique to produce mesoscale structures on the electrolyte surface by spraying deposition of YSZ [27].

In this work we address a different approach to enlarging the electrode-electrolyte contact area in the mesoscale $(10-100 \mu \mathrm{m})$. We used laser machining to modify the surface of a sintered electrolyte in order to engrave a periodic pattern with controlled geometry. The pattern design is defined through a Computer Assisted Design (CAD) file that controls the laser beam. Laser machining of ceramic parts is now an industrial technique widely used in companies and laboratories [28]. Thousands of lasers are incorporated into production lines worldwide and their price is continuously decreasing. Laser machining allows shaping the surface of the electrolytes with a versatility, accuracy and reproducibility unattainable using conventional ceramic techniques. In fact, we have previously used this technique for preparing thin and self-supporting electrolytic membranes for SOFCs [29]. We have previously reported that the slight roughness produced by the laser ablation mechanism on YSZ surfaces, probably combined with the coating of nanoparticles resulting from the machining procedure, caused a decrease in the cathodic polarisation of about $5 \%$ in the 650 $850{ }^{\circ} \mathrm{C}$ temperature range [30]. This experimental finding reinforced our initial assumption that laser machining could be an appropriate technique for increasing the density of oxygen reduction reaction (ORR) sites at the cathode. Furthermore, laser machining allow us to obtain repeatable periodic microstructures that are very convenient for comparing the experimental results with model calculations obtained under periodic boundary conditions.

In this paper we first describe how to machine the surface of sintered YSZ plates to get an enlargement of the electrolyte-cathode contact area. Then, we deposited LSM-YSZ composite cathodes, in which pressure assisted sintering was needed to obtain good contact of the solid phases at the electrolyte interface. Finally we determined the cathode polarisation from Electrochemical Impedance Spectroscopy studies of symmetrical cells and compared the 
electrochemical results with the estimations of the contact area enlargement from confocal optical profilometry.

\section{Materials and Methods}

The electrolyte substrates were obtained from of $8 \mathrm{YSZ}\left(\mathrm{ZrO}_{2}\right.$ doped with $\left.8 \mathrm{~mol} \% \mathrm{Y}_{2} \mathrm{O}_{3}\right)$ Kerafol GmbH (Germany) dense plates. The original commercial plates were $50 \times 50 \mathrm{~mm}^{2}$ in size, $150 \pm 15 \mu \mathrm{m}$ thick and with an ionic conductivity of about $10 \mathrm{~S} / \mathrm{m}$ at $850{ }^{\circ} \mathrm{C}$. The laser used for the surface modification was a commercial Q-switched diode-pumped laser from Rofin (model PowerLine S3 SHG, Germany) emitting at a wavelength of $\lambda=532 \mathrm{~nm}$ (green region) and with a minimum pulse width of $5 \mathrm{~ns}$. Its nominal power was $2 \mathrm{~W}$, the beam type $\mathrm{TEM}_{00}$, the quality factor $\mathrm{M}^{2}<1.2$ and the repetition rate range $15-400 \mathrm{kHz}$. The laser was equipped with a set of galvanometric mirrors to deflect the beam and scan the surface of the sample. These mirrors were computer-controlled through CAD environment software that can use vector or image files (in bitmap format) to manage the beam movement, allowing different results to be obtained in the surface modification of the material. The focal distance of the laser lens was $100 \mathrm{~mm}$, with which we reached a minimum laser spot of $3.4 \mu \mathrm{m}$ and maximum machinable area of $60 \times 60 \mathrm{~mm}^{2}$. Optical-grade mechanical components were used to position both the sample and the laser system.

The laser-modified surfaces were characterized using a model Sensofar PL $\mu 2300$ optical confocal profilometer (from Nikon, Japan) equipped with X20, X50 and X100 lens objectives. The pixel size was $0.830,0.332$ and $0.166 \mu \mathrm{m}$ and the in-depth resolution 1.0, 0.2 and $0.2 \mu \mathrm{m}$ for the X20, X50 and X100 objectives respectively. The surface areas were calculated from the optical profiles using a triangulation algorithm in Matlab code after smoothing the data using a Gaussian filter to supress the noise [31]. The microstructure was studied using a field emission scanning electron microscope (FESEM model Merlin from Carl Zeiss, Germany) equipped with an Energy Dispersive Spectroscopy (EDS) INCA-350 system (Oxford Instruments, United Kingdom). To avoid charging the SEM specimens were coated with Pt or $\mathrm{C}$ for secondary or backscattering electron images respectively. Image analysis and EDS chemical maps were obtained on polished samples, using the materialographic preparation methods described in reference [32]. Image analysis was performed using the Digital Micrograph software from Gatan Inc. (Pleasanton, CA, USA).

The Electrochemical tests were done on $\emptyset 15 \mathrm{~mm}$ button-type standard symmetrical cells. For this purpose, we cut by laser electrolyte substrates that were previously laser-engraved on both sides. The SOFC cathodes were LSM/YSZ 50/50 vol\% as functional layer and 80/20 
vol\% as current collector layer. They were deposited on both surfaces of the YSZ electrolyte plates by dip coating according to the procedure described in reference [33]. Pressure-assisted sintering was performed by placing a weighted alumina boat on top of the specimen covered by YSZ powder inside the furnace. Samples were painted with $\mathrm{Pt}$ or Au paste to improve current collection and mounted on a button-cell test rig (model Probostat from NorECs, Norway) for electrochemical testing. The electrochemical measurements were obtained using a Zahner Zennium workstation (ZAHNER-elektrik GmbH \& Co. KG, Germany) at temperatures between 700 and $900{ }^{\circ} \mathrm{C}$. The sinusoidal signal amplitude was $20 \mathrm{mV}$ and the frequency range was varied from $100 \mathrm{kHz}$ to $0.1 \mathrm{~Hz}$.

\section{Results and Discussion}

\subsection{Comparison of different patterning geometries}

\subsubsection{Laser processing by vector scanning}

As a first approach we laser-machined 3 different geometries on the surfaces of 8YSZ plates, as shown in Fig. 1. To minimize the thermal effects on the YSZ membrane during laser ablation we used the minimum available pulse width in our laser source, $5 \mathrm{~ns}$, by selecting the minimum repetition rate $(15 \mathrm{kHz})$, because in Q-switch type lasers the pulse width increases with the repetition rate [34]. The pulse energy in these conditions was $67 \mathrm{~mJ}$. The surface scanning was performed using the scanning vector mode, where the multiplication of the scan speed $\left(V_{S}\right)$ and the repetition rate $(R)$ defines the distance between the spots along the scanning lines $\left(a=R \cdot V_{s}\right)$, while the separation between the lines (d) is an independent geometrical parameter, as indicated in Fig. 1a.

The first type of surface was obtained with $V_{s}=150 \mathrm{~mm} \cdot \mathrm{s}^{-1}$, whereas the parameter $d=10 \mu \mathrm{m}$ was selected to match the distance along the scanning lines (a), in order to get homogeneous texture. The sample was placed $450 \mu \mathrm{m}$ underfocus to maximize the removal rate [35]. The area irradiated in every pulse is about $10 \mu \mathrm{m}$, larger than the $3.4 \mu \mathrm{m}$ of the beam size in focus position. In these conditions the surface receives enough irradiance to evaporate the material. The laser spots, $10 \mu \mathrm{m}$ apart along both scanning directions, overlap producing a low roughness surface $\left(\mathrm{R}_{\mathrm{a}} \sim 1.5 \mu \mathrm{m}\right)$ with no measurable periodicity (Fig. 1b). For this reason we named this surface Laser-flat (the removed thickness is about $5 \mu \mathrm{m}$, negligible in comparison with the $150 \mu \mathrm{m}$ of the original plate). For the second case (Tracks20), the scan speed was maintained and the distance between lines was increased to $d=20 \mu \mathrm{m}$. The sample position was also modified to $150 \mu \mathrm{m}$ underfocus to reduce the spot overlapping. Thus, a surface with 
parallel tracks was obtained, as shown in Fig. 1c. The peak-to-valley distance was $\sim 6.5 \mu \mathrm{m}$ and the overall contact area calculated from the optical profiles was $A / A^{\prime} \sim 1.23$. In the third case (Dots20), the separation lines $(d=20 \mu \mathrm{m})$ and the sample position $(150 \mu \mathrm{m}$ underfocus) were maintained, but the scan speed was increased to $V_{s}=300 \mathrm{~mm} \cdot \mathrm{s}^{-1}$ to obtain the square array of dots shown in Fig. 1d. In this case the dot separation was $20 \mu \mathrm{m}$ and the peak-to valley distance $\sim 4.5 \mu \mathrm{m}$, leading to an overall contact area of $A / A \sim 1.13$. The surface treatment rate for the latter condition is $6 \mathrm{~mm}^{2} \cdot \mathrm{s}^{-1}$. We would like to point out that, although it would be possible to engrave deep grooves or holes in the electrolyte, in the range of several tens of microns, to get higher $A / A$ ' values, we have intentionally limited the laser machining to depths below $10 \mu \mathrm{m}$. The idea behind this is that this study could be applied not only to electrolyte supported cells with thickness in the range of $\sim 100 \mu \mathrm{m}$, but also to anodesupported cells with electrolyte thickness $\sim 15-20 \mu \mathrm{m}$.
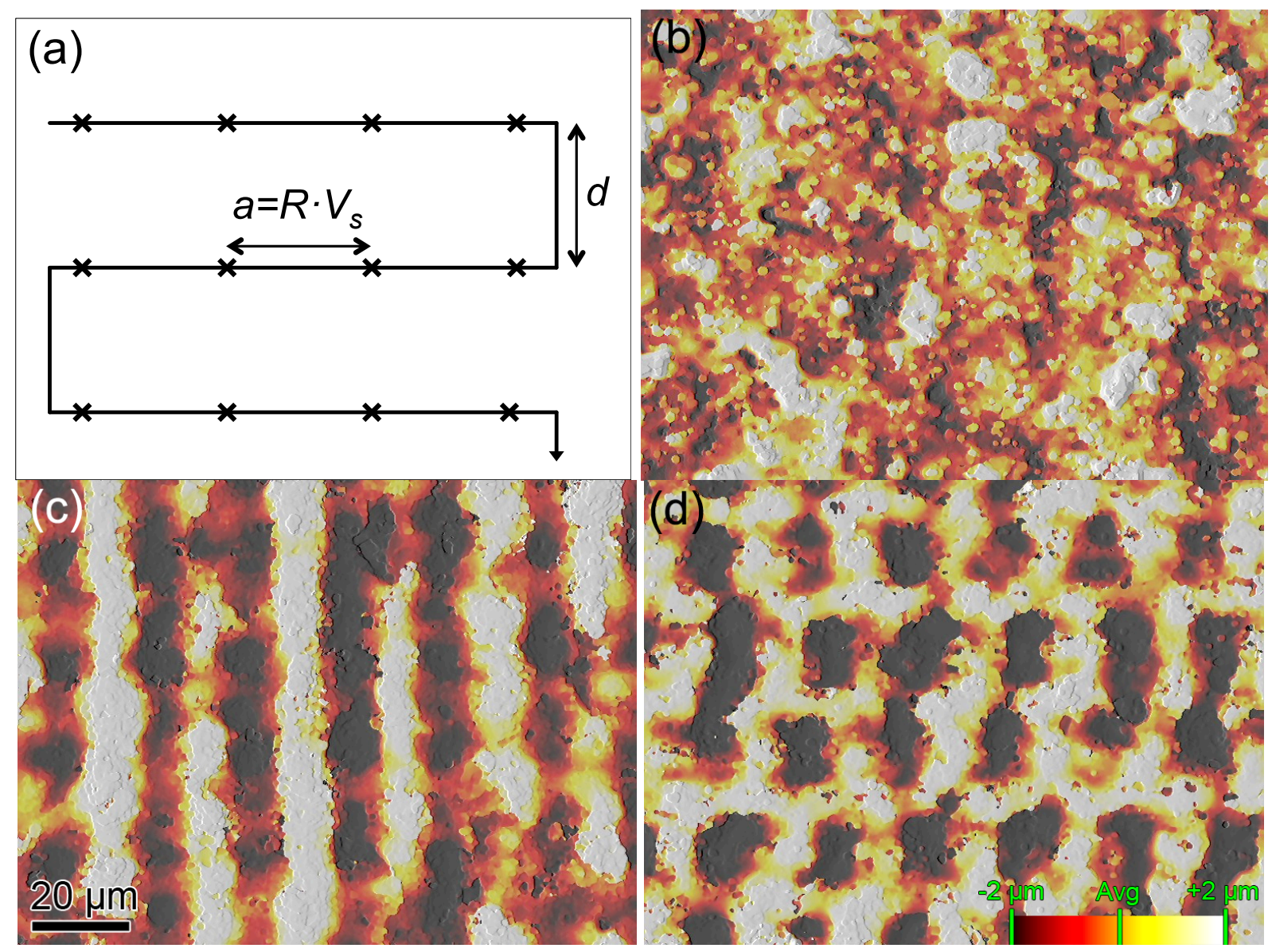

Fig. 1. a) Schematic of the vector scanning procedure. b) Optical profile of a rough surface with no periodic pattern obtained by overlapping close parallel tracks (Laser-flat, $V_{s}=150$ $\left.\mathrm{mm} \cdot \mathrm{s}^{-1}, d=10 \mu \mathrm{m}\right)$. c) Optical profile of parallel tracks $20 \mu \mathrm{m}$ apart (Tracks $\left.20, V_{s}=150 \mathrm{~mm} \cdot \mathrm{s}^{-1}\right)$. d) Optical profile of the square array of dots $20 \mu \mathrm{m}$ apart (Dots20, $V_{s}=300 \mathrm{~mm} \cdot \mathrm{s}^{-1}$ ). The colour scale and the magnification scale marker are the same in all the images. 


\subsubsection{Polarisation resistance of the different surfaces}

The polarisation resistance values of LSM-YSZ /YSZ/LSM-YSZ symmetrical cells prepared with these 3 different contact surfaces, as well as one with no modified surface as blank sample $\left(\mathrm{R}_{\mathrm{a}}=300 \mathrm{~nm}\right)$, are summarized in Table 1. The polarisation resistance decreases as a result of the laser machining of the electrolyte surface. For the so-called laser-flat surface we obtain a slight decrease in polarization, on average $\sim 5 \%$ in the $700-850{ }^{\circ} \mathrm{C}$ range, due to the minor surface increase as a result of the increased roughness. On the other hand, for the other two surfaces with enlarged area, polarisation resistance decreases by about $18 \%$ in the same temperature range. At first, one might have expected a better performance from the dot surface because intuitively the contact surface with the cathode would seem to be higher. However, due to the laser processing method by vector scanning, the parallel tracks of Fig. 1c are deeper than the dots of Fig. 1d and, as a consequence, the contact surface for this dotted surface is lower.

\section{Table 1.}

Polarization resistance measured at different temperatures on symmetrical cells with different laser-modified electrolyte surfaces using vector scanning. No pressure was applied during electrode sintering. The average variation is calculated with respect to the blank cell. The surface area related to that of the blank surface (unmachined), as well as the peak-to-valley distances (depth) measured from confocal optical profilometry (X20 objective, $\sigma=1$ Gaussian filtering), are indicated in the two last rows.

\begin{tabular}{|c|c|c|c|c|}
\hline \multirow[b]{2}{*}{$\begin{array}{c}\text { Temperature } \\
\left({ }^{\circ} \mathrm{C}\right)\end{array}$} & \multicolumn{4}{|c|}{ Polarization resistance $\left(\Omega . \mathrm{cm}^{2}\right)$} \\
\hline & Blank surface & $\begin{array}{c}\text { Laser-Flat } \\
\mathrm{V}_{\mathrm{s}}=150 \mathrm{~mm} \cdot \mathrm{s}^{-1} \\
\mathrm{~d}=10 \mu \mathrm{m} \\
\text { Fig. } 1 \mathrm{~b}\end{array}$ & $\begin{array}{c}\text { Tracks20 } \\
\mathrm{V}_{\mathrm{s}}=150 \mathrm{~mm} \cdot \mathrm{s}^{-1} \\
\mathrm{~d}=20 \mu \mathrm{m} \\
\text { Fig. } 1 \mathrm{c}\end{array}$ & $\begin{array}{c}\text { Dots20 } \\
\mathrm{V}_{\mathrm{s}}=300 \mathrm{~mm} \cdot \mathrm{s}^{-1} \\
\mathrm{~d}=20 \mu \mathrm{m} \\
\text { Fig. } 1 \mathrm{~d}\end{array}$ \\
\hline 650 & 4.03 & 3.85 & 3.81 & 3.68 \\
\hline 700 & 1.94 & 1.80 & 1.69 & 1.65 \\
\hline 750 & 0.98 & 0.92 & 0.81 & 0.79 \\
\hline 800 & 0.53 & 0.50 & 0.41 & 0.41 \\
\hline 850 & 0.29 & 0.28 & 0.20 & 0.21 \\
\hline $\begin{array}{l}\text { Average } \\
\text { variation }\end{array}$ & - & $-5.4 \%$ & $-18 \%$ & $-18 \%$ \\
\hline \multicolumn{5}{|c|}{ Surface geometry } \\
\hline Depth $(\mu \mathrm{m})$ & - & - & 6.5 & 4.5 \\
\hline Surface $\left(A / A^{\prime}\right)$ & 1.00 & $\sim 1.00$ & 1.23 & 1.13 \\
\hline
\end{tabular}




\subsection{Square lattice patterns}

\subsubsection{Laser processing by bitmap scanning}

In order to further increase the electrode-electrolyte contact area, as well as to analyse the physical origin of the polarisation decrease, a different surface processing method was explored, where the laser scanning is defined by bitmap images. The laser engraves spots on the ceramic surface following a bitmap pattern in which the spot separation is controlled by changing the image resolution. The pattern may be repeated as many times as required, assuring exact coincidence of the spot position. Thus this method is more accurate than vector scanning because it is not affected by the mechanical inertias of the galvanometric heads. In this particular case the pattern consisted of a square array of dots, similar to that of Fig. 1d, but with a lattice parameter of $28 \mu \mathrm{m}$ (Dots 28$)$. The pattern was repeated 3 times, resulting in a surface treatment rate of $2.8 \mathrm{~mm}^{2} \cdot \mathrm{s}^{-1}$ per repetition, faster than the vector scanning procedure for Dots20 if we only consider one repetition. As can be observed in Fig. 2, laser irradiation produced $7 \mu \mathrm{m}$ depth cone-shaped holes with diameters of approximately 26-27 microns (almost the entire lattice parameter). The melted and evaporated material from the holes did not spread out completely and was deposited on the hole walls and peripheries. In this way the surface area was enlarged by a factor $A / A \sim 1.2$ with respect to the unprocessed surface, as calculated from the optical profile. It should be noted that the differences in surface topology between figures $2 \mathrm{a}$ and $2 \mathrm{~b}$ are due to the very different probe-surface interaction (electrons and photons) and, consequently, to its very different spatial resolution. Light scattering produces the spurious peaks that can be observed in the optical profile.
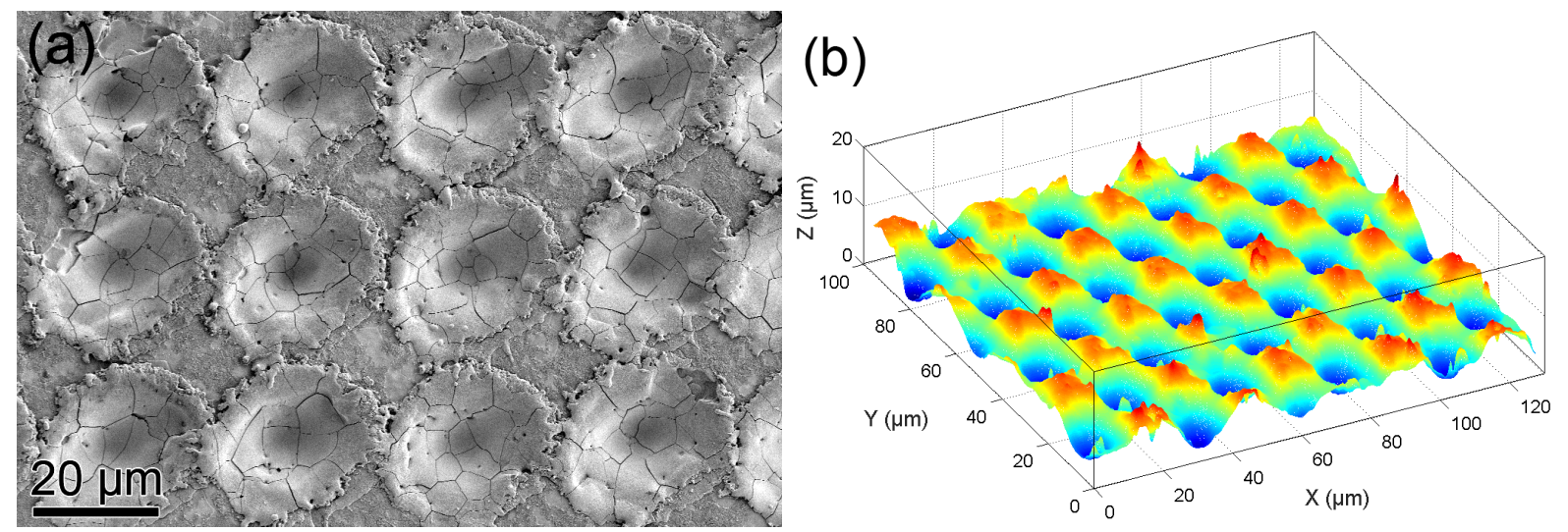

Fig. 2. a) SEM image and (b) 3D optical profile of a YSZ surface. Square array pattern engraved by laser using the bitmap scanning procedure (Dots 28 , lattice parameter $\mathrm{a}=28 \mu \mathrm{m}, 3$ repetitions). 


\subsubsection{Pressure-assisted sintering}

When increasing the depth of the holes, electrode sintering becomes difficult. In Fig. 3 we show SEM cross-section images of the cathode-YSZ interface after the dip-coating deposition (Fig. 3a) and after sintering (Fig. 3b). Although wetting seems adequate in the green state, the contact after sintering is poor in the deeper areas, showing significant electrode-electrolyte debonding. This debonding increases the cathode polarisation, leading to the opposite effect to that which we intended. In conventional sintering of electrodes over flat surfaces, electrode densification takes places only in the vertical direction by a constrained sintering mechanism, producing biaxial compressive stress on the supporting membrane [36]. The stress produced is usually below $10 \mathrm{MPa}$ [37] and, accordingly, it is not a source of concern for causing interfacial delamination or electrolyte cracking. However, on wavy surfaces, the combination of the lateral and vertical stresses caused by the volume reduction during sintering can produce interfacial debonding in the valleys of the wavy contact area, as illustrated in Fig. 4 and experimentally shown in Fig. 3.

Consequently, in order to improve the adhesion, we have employed pressure-assisted sintering to maintain the contact throughout the whole wavy interface. Pressure-assisted techniques have been widely used for sintering of ceramics, mainly to reduce the densification temperature and final grain size [38]. However, in our case we have to bear in mind that we must not lose cathode porosity, as this would produce gas diffusion problems and increase the concentration polarisation. Thus, we applied very low pressures during sintering and we verified, by image analysis in SEM cross-sections, that both pressure- and pressurelesssintered samples present the same porosity $(41 \pm 1 \mathrm{vol} \%)$. In addition, we characterized the phase distribution of the cathode using EDS X-ray maps in the SEM, as shown in Fig. 5. The volume percentage estimations and the phase distribution confirmed that the low load applied during sintering did not significantly modify the microstructure of the cathode.

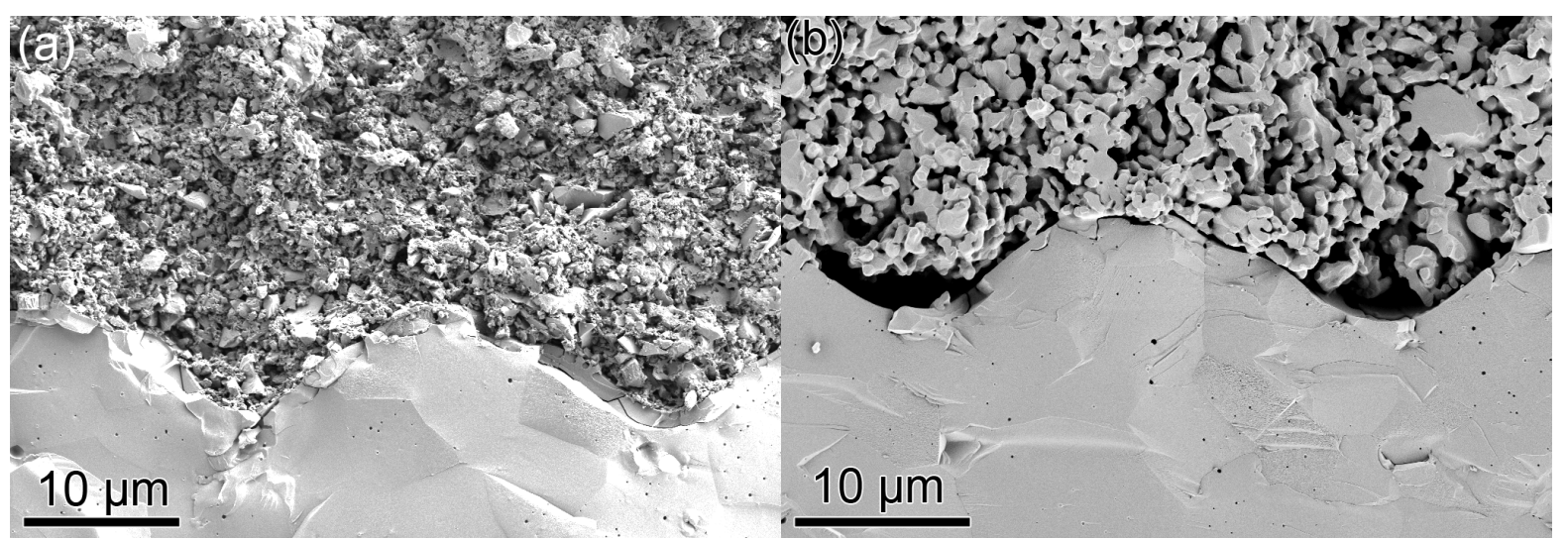


Fig. 3. Electrolyte-cathode interfacial area of the machined surfaces described in Fig. 2 (Dots28). a) In the green state. b) After sintering.
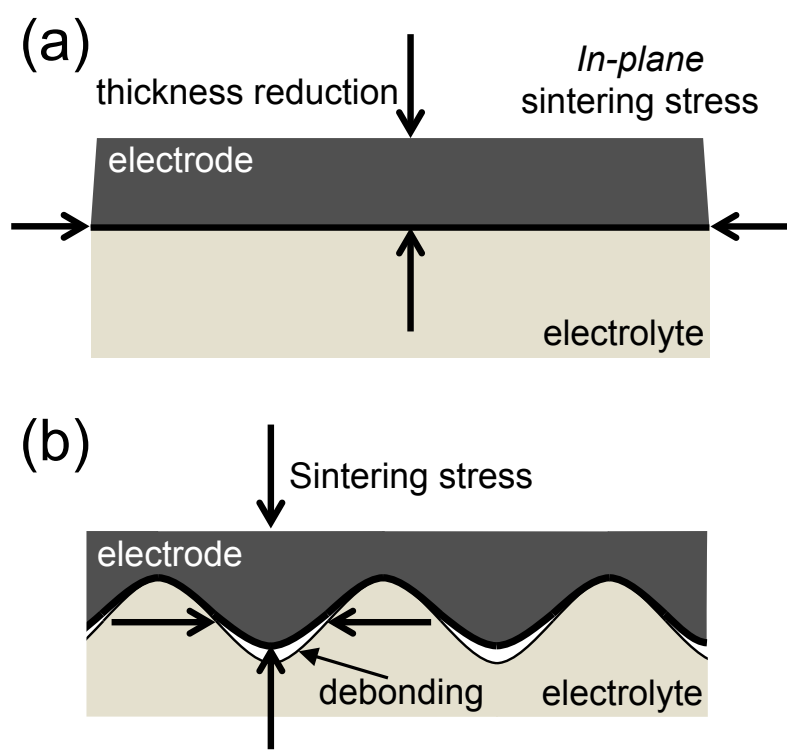

Fig. 4. a) Sintering-induced stresses for the flat conventional case and (b) for sintering of the electrode over a wavy surface.

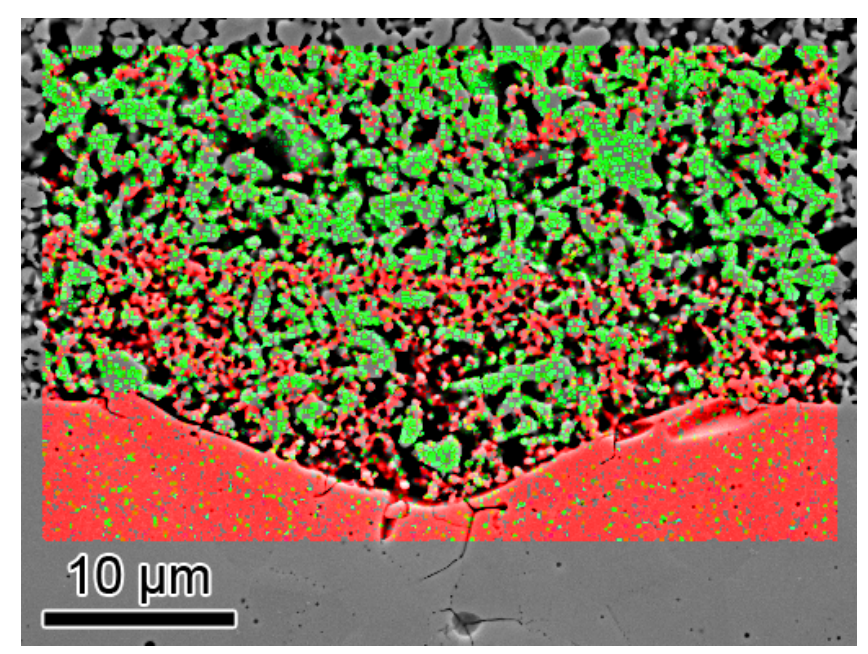

Fig. 5. EDS X-ray map showing the phase distribution in the pressure-assisted sintered double layer cathodes (Dots $\left.28, \mathrm{P}=25 \mathrm{~g} / \mathrm{cm}^{2}\right)$. In red the $\mathrm{YSZ}$ phase $\left(\mathrm{Zr}-\mathrm{L}_{\alpha 1}\right.$ characteristic line $)$ and in green the LSM phase $\left(\mathrm{La}-\mathrm{L}_{\alpha 1}+\mathrm{Mn}-\mathrm{K}_{\alpha 1}\right.$ lines $)$. Beam energy $12 \mathrm{kV}$.

\subsubsection{Polarisation resistance of the square patterned cells}

The cathode polarisation values of symmetrical cells using pressure-assisted sintering are collected in Table 2. First, we have to point out that the applied pressure does not modify the results obtained in the blank cells, coinciding with the microstructural analysis presented in section 3.2.2. In the temperature range analysed the average difference between the blank cells sintered with pressure and sintered without pressure was $0.36 \%$. On the other hand, the 
decreasing trend of the polarisation resistance of cells with wavy surfaces is evidenced from the results of Table 2. The machined cells sintered with no pressure (Dots $28 \mu \mathrm{m}$, No pressure) presented a much higher polarization resistance $(+301 \%)$ than the blank cell. This is due to the interfacial electrolyte/electrode debonding that was discussed in the precedent section (Pressure-assisted sintering) and that can be observed in Fig. 3. However, the average decrease for the cells sintered at $25 \mathrm{~g} \cdot \mathrm{cm}^{-2}(2.45 \mathrm{kPa})$, with respect to the blank cell sintered with no pressure, was $22.2 \%$ in the temperature range studied. For cells sintered at $50 \mathrm{~g} \cdot \mathrm{cm}^{-2}$ $(4.90 \mathrm{kPa})$ the average decrease was $28.4 \%$. As a first approximation, this decrease could be understood in terms of the area enlargement factor produced by the laser machining. The area enlargement factor, $A / A^{\prime}$, calculated from optical profilometry depends to a small extent on the objective lens used and to a greater extent on the filtering used to eliminate the optical noise. This factor is $A / A^{\prime}=1.3-1.4$, depending on the optical microscope objective, if the data is unfiltered. But it is approximately $A / A^{\prime}=1.2$ using $\sigma=1$ or $\sigma=2$ Gaussian algorithms to filter the optical components with characteristic length under $1 \mu \mathrm{m}$ (corresponding to the LSM and YSZ grain size in the cathode). To compare these estimations with the predictions from equations (1) and (2), we have to use the low current density limit of the Butler-Volmer equation, in which it can be considered that the EIS experiments take place. If $\left|\frac{\beta z F \eta_{a c}^{c}}{R T}\right| \ll 1$ and $\left|\frac{(1-\beta) z F \eta_{a c}^{c}}{R T}\right| \ll 1$ a linear relationship between $\eta_{a c}^{c}$ and $j_{o}$ is obtained for Equation (1) [12]:

$\left|\eta_{a c}^{c}\right| \approx \frac{R T}{z F} \frac{j}{j_{0}}$

\section{Table 2.}

Polarization resistance measured at different temperatures on symmetrical cells sintered with different pressures. We include for comparison the data obtained with two unmachined surfaces (Blank) sintered with and without pressure. The geometry of the dotted surface is the one depicted in Fig. 2.

\begin{tabular}{cccccc}
\hline \multicolumn{5}{c}{ Polarization resistance $\left(\mathbf{\Omega . c m} \mathbf{2}^{\mathbf{}}\right)$} \\
\hline $\begin{array}{c}\text { Temperature } \\
\left({ }^{\circ} \mathrm{C}\right)\end{array}$ & $\begin{array}{c}\text { Blank } \\
\text { No pressure }\end{array}$ & $\begin{array}{c}\text { Blank } \\
\mathbf{P}=\mathbf{4 . 9} \mathbf{~ k P a}\end{array}$ & $\begin{array}{c}\text { Dots } \mathbf{2 8} \boldsymbol{\mu m} \\
\text { No pressure }\end{array}$ & $\begin{array}{c}\text { Dots } \mathbf{2 8} \boldsymbol{\mu m} \\
\mathbf{P}=\mathbf{2 . 4 5} \mathbf{~ k P a}\end{array}$ & $\begin{array}{c}\text { Dots } \mathbf{2 8} \boldsymbol{\mu m} \\
\mathbf{P}=\mathbf{4 . 9} \mathbf{~ k P a}\end{array}$ \\
\hline 700 & 2.47 & 2.61 & 5.05 & 2.09 & 1.70 \\
750 & 1.17 & 1.27 & 2.92 & 1.00 & 0.91 \\
800 & 0.54 & 0.55 & 1.87 & 0.43 & 0.41 \\
850 & 0.28 & 0.25 & 1.31 & 0.19 & 0.18 \\
900 & 0.14 & 0.13 & 1.03 & 0.10 & 0.10 \\
\hline Average & - & $\mathbf{- 0 . 3 6 \%}$ & $\mathbf{+ 3 0 1 \%}$ & $\mathbf{- 2 2 . 2 \%}$ & $\mathbf{- 2 8 . 4 \%}$ \\
variation & - & &
\end{tabular}


Thus, a polarisation decrease of about $30 \%$ should come from an area enlargement of the same magnitude. Although a very good matching result for the data obtained from the unfiltered optical profiles, we believe that in this case the area enlargement factor is overestimated. Despite the confocal configuration of the optical profilometer, optical scanning of transparent materials, such as the YSZ, introduces noise at the level of the diffraction limit $\sim 0.2-0.3 \mu \mathrm{m}$. If it is not filtered this noise makes a significant contribution to the area when the triangulation algorithm is applied. Accordingly, we applied a Gaussian filtering to smooth the data before the area calculation. For the X100 objective the pixel size was $0.166 \mu \mathrm{m}$ and thus we used a $\sigma=2$ filter to include a matrix of $6 x 6$ pixels (equivalent to $1 \times 1 \mu \mathrm{m}^{2}$ ) with a weight in the smoothing algorithm higher than $60 \%$ of the central pixel. As a consequence, we consider that a more realistic estimation of the area enlargement factor of the Dots 28 surface might be in the range of $A / A^{\prime}=1.2$, which does not match so well with the resistance polarisation decrease. It may be that the laser machining not only enlarges the electrodeelectrolyte contact area in the mesoscale, but also modifies its nature in some way yet to be analysed. The coating of nanoparticles resulting from the machining procedure [29] could also contribute to the decrease of the cathodic polarisation. However, a more detailed study by finite element analysis of the electrochemical response of mesoscale-corrugated cells is required to fully understand these processes [39],[40].

\subsubsection{Electrochemical Impedance Spectroscopy of the square patterned cells}

To further explore this issue, Nyquist plots for the different samples at 700 and $900{ }^{\circ} \mathrm{C}$ are shown in Fig. 6, and a summary of the fitting parameters is also shown in Table 3. In general, analysis of LSM-YSZ composite electrodes is difficult, as there is disagreement in the literature about the mechanism and kinetics for oxygen reduction reaction (ORR). For example, Jørgensen and Mogensen [41] found that there are at least five processes in the oxygen reduction reaction. From high to low frequency these processes are: $(i)$ and (ii) transport across LSM/YSZ interfaces and through the YSZ of the composite; (iii) surface diffusion; (iv) gas diffusion, and (v) an activation process at the TPBs. In addition, Kim et al. [42] proposed that the ORR is limited by oxygen ions transfer and surface diffusion. On the contrary, Murray et al. [43] concluded that the reaction is limited by oxygen adsorption and dissociation. Finally, Nielsen and Hjelm [44] performed a very comprehensive review on the impedance of LSM/YSZ cathodes. They suggested that, as Mn is dissolved in the YSZ composite material, an extra arc at high frequencies could be detected, indicating the formation of resistive secondary phases at the LSM/YSZ interface. From all these studies, and 
from many others in the literature, we can conclude that ORR mechanisms are very dependent on the microstructure of the electrode and on the electrode-electrolyte interface.

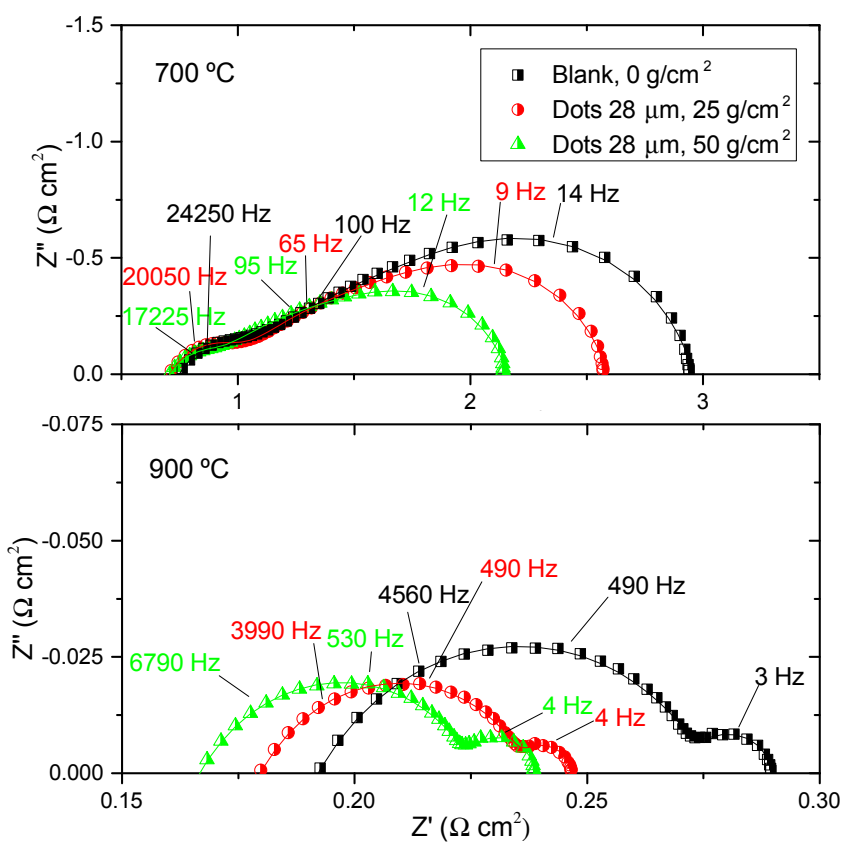

Fig. 6. EIS analysis of the unprocessed and patterned symmetrical cells (Dots 28 ) at $700{ }^{\circ} \mathrm{C}$ (top) and $900^{\circ} \mathrm{C}$ (bottom).

Table 3. Impedance parameters fitted from the EIS experiments. $R_{1}, R_{2}$ and $R_{3}$ correspond to the resistance values of the $(R Q)$ components from the equivalent circuit employed, as described in the text. $R_{4}$ is the resistance of the Warburg element $\left(W_{4}\right)$.

\begin{tabular}{|c|c|c|c|c|c|}
\hline \multirow[b]{2}{*}{ Sample } & \multirow[b]{2}{*}{$\begin{array}{c}\text { Temperature } \\
\left({ }^{\circ} \mathrm{C}\right)\end{array}$} & \multicolumn{4}{|c|}{ Polarization resistance $\left(\Omega . \mathrm{cm}^{2}\right)$} \\
\hline & & $\mathbf{R}_{1}\left(\Omega \mathrm{cm}^{2}\right)$ & $\mathbf{R}_{2}\left(\Omega \mathrm{cm}^{2}\right)$ & $\mathbf{R}_{3}\left(\Omega \mathrm{cm}^{2}\right)$ & $\mathrm{R}_{4}\left(\mathbf{\Omega} \mathrm{cm}^{2}\right)$ \\
\hline \multirow{5}{*}{$\begin{array}{c}\text { Blank } \\
\mathbf{P}=0 \mathrm{kPa}\end{array}$} & 700 & $0.59 \pm 0.02$ & $0.88 \pm 0.10$ & $1.00 \pm 0.06$ & - \\
\hline & 750 & $0.35 \pm 0.02$ & $0.34 \pm 0.04$ & $0.43 \pm 0.04$ & - \\
\hline & 800 & $0.11 \pm 0.02$ & $0.27 \pm 0.02$ & $0.16 \pm 0.01$ & - \\
\hline & 850 & - & $0.14 \pm 0.01$ & $0.140 \pm 0.002$ & $0.009 \pm 0.001$ \\
\hline & 900 & - & $0.08 \pm 0.01$ & $0.040 \pm 0.003$ & $0.014 \pm 0.001$ \\
\hline \multirow{5}{*}{$\begin{array}{c}\text { Dots28 } \\
\mathbf{P}=0 \mathrm{kPa}\end{array}$} & 700 & $0.87 \pm 0.02$ & - & $2.85 \pm 0.04$ & $1.33 \pm 0.02$ \\
\hline & 750 & $0.65 \pm 0.01$ & - & $1.12 \pm 0.01$ & $1.15 \pm 0.01$ \\
\hline & 800 & $0.37 \pm 0.01$ & - & $0.45 \pm 0.01$ & $1.05 \pm 0.01$ \\
\hline & 850 & $0.22 \pm 0.01$ & - & $0.18 \pm 0.01$ & $0.92 \pm 0.01$ \\
\hline & 900 & $0.14 \pm 0.01$ & - & $0.08 \pm 0.01$ & $0.82 \pm 0.01$ \\
\hline \multirow{5}{*}{$\begin{array}{c}\text { Dots28 } \\
\mathrm{P}=2.45 \mathrm{kPa}\end{array}$} & 700 & $0.54 \pm 0.02$ & $0.80 \pm 0.10$ & $0.75 \pm 0.06$ & - \\
\hline & 750 & $0.34 \pm 0.02$ & $0.32 \pm 0.02$ & $0.33 \pm 0.04$ & - \\
\hline & 800 & $0.12 \pm 0.01$ & $0.16 \pm 0.01$ & $0.15 \pm 0.01$ & - \\
\hline & 850 & - & $0.10 \pm 0.01$ & $0.080 \pm 0.002$ & $0.005 \pm 0.001$ \\
\hline & 900 & - & $0.06 \pm 0.01$ & $0.030 \pm 0.005$ & $0.009 \pm 0.001$ \\
\hline \multirow{5}{*}{$\begin{array}{c}\text { Dots28 } \\
\mathrm{P}=4.9 \mathrm{kPa}\end{array}$} & 700 & $0.50 \pm 0.03$ & $0.64 \pm 0.06$ & $0.56 \pm 0.05$ & - \\
\hline & 750 & $0.32 \pm 0.03$ & $0.28 \pm 0.03$ & $0.31 \pm 0.03$ & - \\
\hline & 800 & $0.09 \pm 0.01$ & $0.21 \pm 0.01$ & $0.11 \pm 0.01$ & - \\
\hline & 850 & - & $0.09 \pm 0.01$ & $0.09 \pm 0.01$ & $0.010 \pm 0.001$ \\
\hline & 900 & - & $0.05 \pm 0.01$ & $0.04 \pm 0.01$ & $0.013 \pm 0.001$ \\
\hline
\end{tabular}


In our case, the equivalent circuit employed to fit the impedance data was $L-R_{0}-(R Q)_{1}$ $(R Q)_{2}-(R Q)_{3}-W_{4}$, where $L$ is an inductance, $R$ is a resistance, $Q$ is a constant phase element and $W$ a Warburg element. $W_{4}$ component is not present for the low temperature range (700$\left.800^{\circ} \mathrm{C}\right)$, whereas at the high temperature range $\left(900-850^{\circ} \mathrm{C}\right)(R Q)_{1}$ disappears. For the Dots 28 sample sintered with no pressure, $(R Q)_{2}$ and $(R Q)_{3}$ components seem to be overlapped. This sample presents the higher polarisation resistance values as a consequence of a poor contact at the electrode/electrolyte interface. This is also consistent with SEM images shown in Fig. 3. For these reasons, this sample will not be considered for the subsequent comparison analysis.

Based on the aforementioned literature data, the first component $(R Q)_{1}$, with capacitance values in the range of $10^{-5} \mathrm{~F} \cdot \mathrm{cm}^{-2}$ and summit frequencies of about $10-20 \mathrm{kHz}$, can possibly be explained by the presence of secondary phases near the electrode-electrolyte interface as previously reported [44], because our cathodes were sintered at a relatively high temperature $\left(1150^{\circ} \mathrm{C}\right)$. The second component $(R Q)_{2}$ showed capacitance values in the range of $10^{-3} \mathrm{~F} \cdot \mathrm{cm}^{-}$ 2 and summit frequencies ranging from 100 to $5000 \mathrm{~Hz}$, and it was associated to ionic transport in the YSZ matrix from the TPB to the electrode/electrolyte interface. The third component $(R Q)_{3}$, with capacitance values in the range of $10^{-2} \mathrm{~F} \cdot \mathrm{cm}^{-2}$ and summit frequencies of $10-500 \mathrm{~Hz}$, was assigned to the coupled processes of dissociative adsorption of oxygen and surface diffusion of oxygen species. Finally, the forth component $W_{4}$, appearing above $800{ }^{\circ} \mathrm{C}$, with capacitance values in the range of $5 \mathrm{~F} \cdot \mathrm{cm}^{-2}$ and summit frequencies of about 3 $\mathrm{Hz}$, was fitted using a Finite-Length-Warburg impedance element, which appears for well performing cathodes and is ascribed to gas diffusion and conversion.

If we compare the resistance values in Table 3, we observe that $R_{1}$ is almost constant for the blank and the machined samples, as this contribution is due to secondary phases, which are supposed to be similar for the different samples. However, $R_{2}$ and $R_{3}$ (both ascribed to activation processes) decreases for the machined samples in comparison with the blank sample, due to the increased surface area. In addition, polarisation resistance values also decrease with the assisted pressure during sintering, as a consequence of better contact between YSZ and LSM-YSZ, as observed in Fig. 7. 

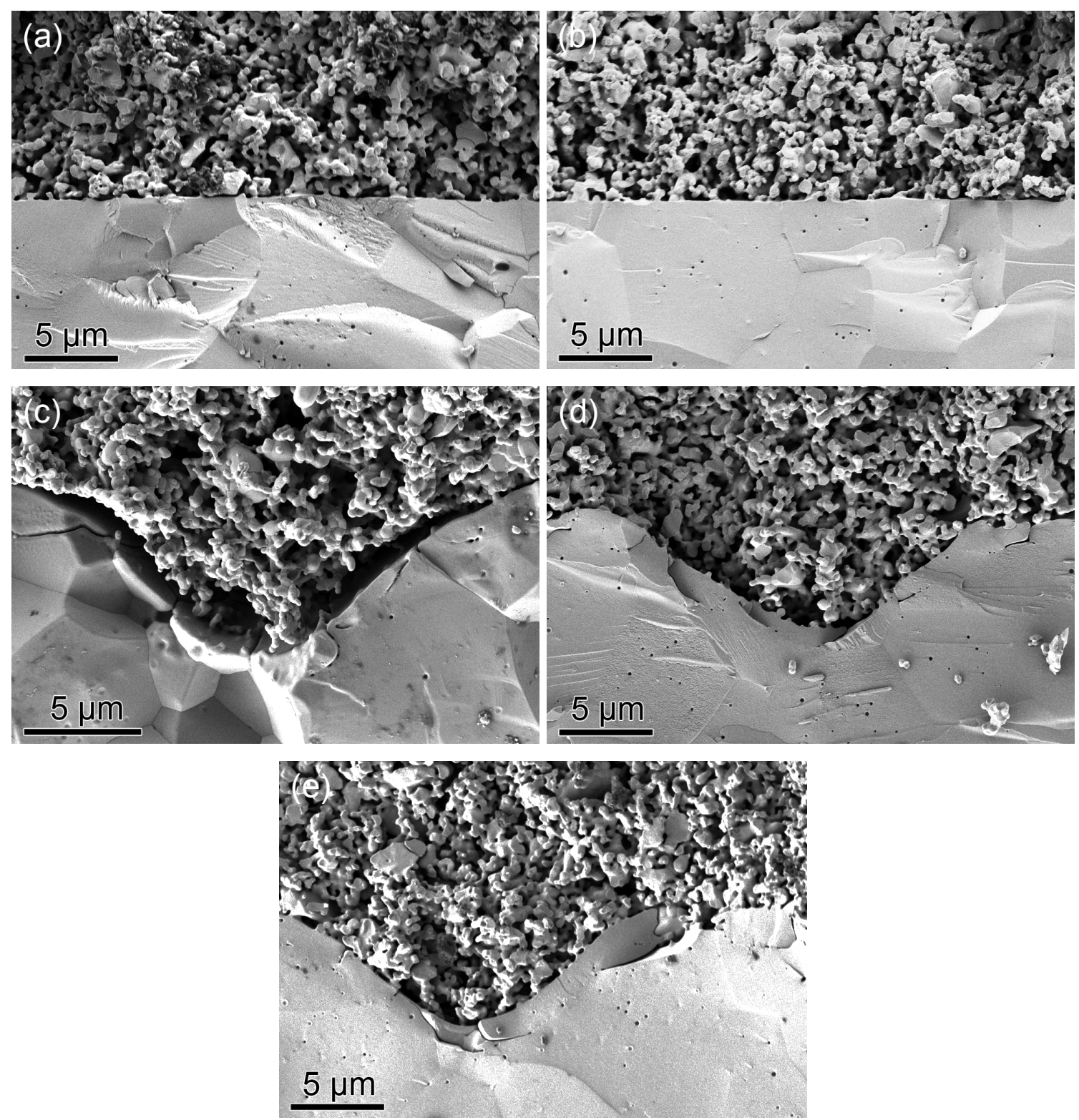

Fig. 7. SEM cross-section images of the electrolyte-cathode interfacial area of the unprocessed and machined surfaces. (a) Blank surface, no pressure. (b) Blank surface, $\mathrm{P}=4.9$ kPa. (c) Dots 28 , no pressure. (d) Dots $28, \mathrm{P}=2.45 \mathrm{kPa}$. (e) Dots28, $\mathrm{P}=4.9 \mathrm{kPa}$.

\section{Conclusion}

Laser micro-patterning has been demonstrated as a useful tool for reducing the cathode polarisation of Solid Oxide Fuel Cells by increasing the electrode-electrolyte contact surface. We modified the surface of YSZ sintered plates using a nanosecond pulsed laser emitting in the green region. The pattern engraved on the electrolyte surface is defined by the CAD software that controls the laser beam by means of a set of galvanometric mirrors. In this way we engraved a micro-pattern with periodicity in the range $20-30 \mu \mathrm{m}$ and up to $7 \mu \mathrm{m}$ in depth. According to the laser source and laser optics employed, we could have engraved deeper 
holes to enlarge the contact surface even more, but we limited the depth to under $\sim 10 \mu \mathrm{m}$ so that the method would also be valid for $\sim 15-20 \mu \mathrm{m}$ thick electrolytes on anode supported fuel cells. We have explored two methods of laser machining, namely vector and bitmap scanning, and both methods seemed valid. Vector scanning is generally faster while bitmap scanning is more accurate for repeating the scans ensuring subsequent holes are engraved in exactly the same position. With the surfaces studied in this work, we have prepared symmetrical LSMYSZ/YSZ/LSM-YSZ cells in order to determine the polarisation resistance by Electrochemical Impedance Spectroscopy. To achieve good cathode-electrolyte contact after sintering the electrode, it was necessary to use pressure-assisted sintering with loads of about $5 \mathrm{kPa}$. The low loads used did not modify the electrode microstructure, as verified by image analysis and EDS in the SEM. Despite the moderate area enlargement achieved, which could be significantly increased by optimizing the laser machining procedure, the polarisation resistance values decreased by about $30 \%$ with respect to the unprocessed surfaces. This decrease matches the area enlargement factor calculated from the optical profilometry raw data. However, if the optical noise is suppressed by applying Gaussian filtering, the polarisation decrease is $\sim 50 \%$ higher than the expected value. Finally, EIS analysis confirmed that the components of the equivalent circuit showing reduction regarding the blank sample are those ascribed to activation processes.

This work describes a new technique for the modification of the ceramic component surfaces of a SOFC to reduce the electrode polarisation. Furthermore, laser machining can be applied to the anode or electrolyte surfaces, both in sintered or green-state. For instance if we machine the surface of the anodic support, we could then to deposit thin electrolytes. The method is simple and, as commercial laser sources with shorter pulse widths and different wavelengths are increasingly available in the market, a future technological application would probably not involve a significant extra cost. Furthermore, the method is very appropriate for producing repeatable periodic surfaces easier to model. In fact, further studies on full fuel cells with corrugated electrode-electrolyte surfaces comparing electrochemical experiments with theoretical modelling are in progress.

\section{Acknowledgements}

This work was funded by the MAT2015-68078-R project, which is financed by the Spanish Government (Ministerio de Economía y Competitividad) and the Feder Program of 
the European Union. The authors acknowledge the use of Servicio General de Apoyo a la Investigación-SAI, Universidad de Zaragoza for the electron microscopy facilities.

\section{References}

[1] S.C. Singhal, K. Kendall, High Temperature Solid Oxide Fuel Cells: Fundamentals, Design and Applications, Elsevier, 2003.

[2] N.Q. Minh, Journal of the American Ceramic Society, 76 (1993) 563-588.

[3] S.H. Chan, K.A. Khor, Z.T. Xia, Journal of Power Sources, 93 (2001) 130-140.

[4] V.M. Orera, M.A. Laguna-Bercero, A. Larrea, Frontiers in Energy Research, 2 (2014) 113.

[5] A. Weber, E. Ivers-Tiffee, Journal of Power Sources, 127 (2004) 273-283.

[6] S.B. Adler, Chemical Reviews, 104 (2004) 4791-4843.

[7] Y. Takeda, R. Kanno, M. Noda, Y. Tomida, O. Yamamoto, Journal of the Electrochemical Society, 134 (1987) 2656-2661.

[8] J. Mizusaki, H. Tagawa, K. Tsuneyoshi, A. Sawata, Journal of the Electrochemical Society, 138 (1991) 1867-1873.

[9] E. Wachsman, T. Ishihara, J. Kilner, MRS Bull., 39 (2014) 773-779.

[10] N.F. Bessette, W.J. Wepfer, J. Winnick, Journal of the Electrochemical Society, 142 (1995) 3792-3800.

[11] M. Kishimoto, H. Iwai, M. Saito, H. Yoshida, in: 14th International Heat Transfer Conference, ASME, Washington, DC, USA, 2010, pp. 1-10.

[12] E.Ivers-Tiffée, A.V. Virkar, Electrode Polarisations, in: S.C. Singhal, K. Kendall (Eds.) High Temperature Solid Oxide Fuel Cells: Fundamentals, Design and Applications, Elsevier, 2003.

[13] J. An, J.H. Shim, Y.B. Kim, J.S. Park, W. Lee, T.M. Gur, F.B. Prinz, MRS Bull., 39 (2014) 798-804.

[14] D. Ding, X.X. Li, S.Y. Lai, K. Gerdes, M.L. Liu, Energy \& Environmental Science, 7 (2014) 552-575.

[15] H. Shimada, K. Takizawa, H. Michibata, A. Hagiwara, M. Ihara, Journal of the Electrochemical Society, 162 (2015) F40-F53.

[16] W.Z. Zhu, S.C. Deevi, Materials Science and Engineering a-Structural Materials Properties Microstructure and Processing, 362 (2003) 228-239.

[17] C.-C. Chao, C.-M. Hsu, Y. Cui, F.B. Prinz, Acs Nano, 5 (2011) 5692-5696. 
[18] M. Motoyama, C.C. Chao, J.H. An, H.J. Jung, T.M. Gur, F.B. Prinz, Acs Nano, 8 (2014) 340-351.

[19] T. Ryll, H. Galinski, L. Schlagenhauf, P. Elser, J.L.M. Rupp, A. Bieberle-Hutter, L.J. Gauckler, Advanced Functional Materials, 21 (2011) 565-572.

[20] D. Herbstritt, A. Weber, E. Ivers-Tiffee, Journal of the European Ceramic Society, 21 (2001) 1813-1816.

[21] M. Gao, C.-X. Li, M.-D. Wang, H.-L. Wang, C.-J. Li, Influence of the surface roughness of plasma-sprayed YSZ on LSM cathode polarization in solid oxide fuel cells, in: M.K. Lei, X.P. Zhu, K.W. Xu (Eds.) Surface Engineering, 2008, pp. 641-644.

[22] X.-M. Wang, C.-J. Li, C.-X. Li, G.-J. Yang, Journal of Thermal Spray Technology, 19 (2010) 311-316.

[23] X.-M. Wang, C.-X. Li, J.-Y. Huang, G.-J. Yang, C.-J. Li, International Journal of Hydrogen Energy, 39 (2014) 13650-13657.

[24] Y. Xu, F. Tsumori, T. Osada, H. Miura, Micro \& Nano Letters, 8 (2013) 571-574.

[25] F. Tsumori, Y. Tanaka, Y. Xu, T. Osada, H. Miura, Japanese Journal of Applied Physics, 53 (2014).

[26] F. Tsumori, Y. Xu, Y. Tanaka, T. Osada, H. Miura, Micrometer-scale imprinting process for ceramic sheet from powder compound material, in: T. Ishikawa, K.I. Mori (Eds.) 11th International Conference on Technology of Plasticity, Ictp 2014, 2014, pp. 1433-1438.

[27] H.L. Dai, S.C. He, H. Chen, L.C. Guo, Ceramics International, 42 (2016) 2045-2050.

[28] R. Lahoz, G.F. de la Fuente, J.M. Pedra, J.B. Carda, International Journal of Applied Ceramic Technology, 8 (2011) 1208-1217.

[29] A. Larrea, D. Sola, M.A. Laguna-Bercero, J.I. Pena, R.I. Merino, V.M. Orera, Journal of the Electrochemical Society, 158 (2011) B1193-B1197.

[30] J.A. Cebollero, R. Lahoz, M.A. Laguna-Bercero, J.I. Peña, A. Larrea, V.M. Orera, International Journal of Hydrogen Energy, in press.

[31] J.C. Russ, The Image Processing Handbook, CRC Press, 1995.

[32] S. Serrano-Zabaleta, M.A. Laguna-Bercero, L. Ortega-San-Martin, A. Larrea, Journal of the European Ceramic Society, 34 (2014) 2123-2132.

[33] H. Monzon, M.A. Laguna-Bercero, A. Larrea, B.I. Arias, A. Varez, B. Levenfeld, International Journal of Hydrogen Energy, 39 (2014) 5470-5476.

[34] D. Bäuerle, Laser Processing and Chemistry, 4th ed., Springer-Verlag Berlin Heidelberg, 2011.

[35] D. Sola, A. Escartin, R. Cases, J.I. Pena, Applied Surface Science, 257 (2011) 5413-5419. 
[36] D.J. Green, O. Guillon, J. Rodel, Journal of the European Ceramic Society, 28 (2008) 1451-1466.

[37] A. Atkinson, J.-S. Kim, R. Rudkin, S. Taub, X. Wang, Journal of the American Ceramic Society, 94 (2011) 717-724.

[38] G. Skandan, Nanostruct. Mater., 5 (1995) 111-126.

[39] H. Iwai, A. Kuroyanagi, M. Saito, A. Konno, H. Yoshida, T. Yamada, S. Nishiwaki, Journal of Power Sources, 196 (2011) 3485-3495.

[40] A. Konno, H. Iwai, M. Saito, H. Yoshida, Journal of Power Sources, 196 (2011) 74427449.

[41] M.J. Jorgensen, M. Mogensen, Journal of the Electrochemical Society, 148 (2001) A433A442.

[42] J.D. Kim, G.D. Kim, J.W. Moon, Y.I. Park, W.H. Lee, K. Kobayashi, M. Nagai, C.E. Kim, Solid State Ionics, 143 (2001) 379-389.

[43] E.P. Murray, T. Tsai, S.A. Barnett, Solid State Ionics, 110 (1998) 235-243.

[44] J. Nielsen, J. Hjelm, Electrochimica Acta, 115 (2014) 31-45. 